\title{
Palliative Sedation for Children at End of Life: a Retrospective Cohort Study
}

\author{
Yang Chen \\ West China fourth Hospital Sichuan University \\ Jianjun Jiang \\ West China fourth Hospital Sichuan University \\ Wei Peng \\ West China fourth Hospital Sichuan University \\ Chuan Zhang ( $\square$ 331273145@qq.com) \\ West China fourth Hospital Sichuan University
}

\section{Research Article}

Keywords: palliative sedation, children, palliative care, symptoms control, end of life

Posted Date: December 21st, 2021

DOI: https://doi.org/10.21203/rs.3.rs-1138909/v1

License: (c) (1) This work is licensed under a Creative Commons Attribution 4.0 International License. Read Full License 


\section{Abstract}

Background: Palliative sedation is consciously reducing the patient's consciousness to alleviate the refractory symptoms. However, studies on palliative sedation for children are scarce. We aimed to survey the symptom control and risks for children with sedative therapy in end of life.

Method: This study was a single center retrospective cohort study. Children who died in the Department of Palliative Medicine were divided into palliative sedation (Group A) and non-palliative sedation group (Group B). The symptoms relief, survival time, and last hospitalization time were compared between two groups.

Results: From January 2012 to November 2019, 41 children died in department of palliative care. 24 children were sedated (Group A), meanwhile 17 children were not (Group B). The symptoms in Group A were more complex than Group B ( $p=0.013)$. Overall symptom relief in Group A was higher than that in Group B $(24 / 24,10 / 15 p=0.041)$. Pain relief rates $\varangle 7 / 7,20 / 21 p=0.714 \rrbracket$, maximum/pre-death opioid dose [30(20, 77.5), 18(9, 45) $p=0.175,30(20,60), 18(9,45) p=0.208]$ and pain intensity difference $[5(4,6.5), 4(2,6) p=0.315]$ were not statistically significant difference in both group. After diagnosis, the survival time of the Group A was longer than the Group B $(p=0.047)$. However, the length of hospitalization before death was similar in two groups $(p=0.385)$.

Conclusion: Palliative sedation controls complicated, painful symptoms at the end of life and does not shorten the hospitalization time in children.

\section{Background}

The annual demand for palliative care for children in China ranges from 23 to 24 per 100,000 people [1], with approximately 3,037,950 cases of children have pediatric palliative care needs among 1.3 billion people[2]. In 2017, the Integrated National Mortality Surveillance System, which covers 24 percent of China's population, showed that 90,600 deceased children may benefit from palliative care [3].

Palliative care for children not only improves the physical and psychosocial symptoms of children with limited lives [4, 5], but also benefits those children themselves and their famili[6-10]. There is now an increasing social emphasis on timely intervention in palliative care for children. Palliative care for children could control symptoms, reduce overtreatment and allow for end-of-life preparation of those children. These contribute to improve psychosocial outcomes during parental bereavement ${ }^{[11-13]}$. Various symptoms appear at children's end-of-life, which are intractable, unmanageable and un-relievable, and cause great suffering and distress to children, their families and caregivers[14, 15]. Palliative sedation, which aims to relieve end-of-life refractory symptoms by reducing patient's consciousness, is used in $12-64 \%$ of adults in palliative care ${ }^{[16-18]}$ and in $48.4 \%$ of adults who die in hospital[19]. Although there has been demonstrated benefit of better symptom control in patients with a terminal illness, palliative sedation continues to gather some controversy[20, 21].

In the available studies, palliative sedation in children has been reported as an isolated case and experience sharing[22-25], and there is a lack of effect and safty evidence for palliative sedation in children. The aim of this study was to reveal the sedation procedure, symptom control and risks for children in end of life, in order to enrich the practical experience for children palliative sedation.

\section{Methods}

\subsection{Patients}

We retrospectively recorded pediatric patients admitted to the palliative care department of our hospital between January 2012 and November 2019. Inclusion criteria: 1. Age 0-18; 2. Received palliative care; 3. Died during hospitalization. Exclusion criteria: 1 . Age >18; 2 . No death during hospitalization; 3. Information is incomplete.

\subsection{Methods}

1.2.1 Group: Children were divided into palliative sedation group (Group A) and non-palliative sedation group (Group B) according to whether used sedative drugs (midazolam, chlorpromazine), comparing the demographic characteristics, principal diagnosis, types of symptoms and hydration of two groups at admission.

1.2.2 Observation: Information about symptoms relief, pain, dyspnea, survival time after diagnosis, and last hospitalization time was extracted from the electronic medical record. Symptoms mentioned in the medical records were recorded, such as pain, dyspnea, irritability, coma, convulsions, vomiting, and fever.

Description of pain was pain intensity difference (PID), pain relief rate, and pain relief (PAR) ${ }^{[26]}$. Pain intensity (PI) assessments used FLACC scale scores, Wang-Baker faces pain rating scales, or numerical rating scales (NRS), according to ages and ability of cognitive. Analgesic drugs (initial dose, maximum dose, pre-death dose and route), pain relief, and length of sleep were recorded. Dose of opioids every $24 \mathrm{~h}$ converted to oral 
morphine (conversion rate, oral morphine: intravenous morphine $=3: 1$, oral morphine: subcutaneous morphine $=2: 1$, oral morphine: fentanyl transdermal $(25 \mathrm{mcg} / \mathrm{h}$ patch $)=60: 25$, oral morphine: oral oxycodone $=2: 1)$ [27-29]. Pain intensity difference (PID) meaned the difference between the pain score at the beginning of the administration of analgesics and the pain score at each time point. Pain relief (PAR) grading: not alleviated; mild relief (pain relief about 1/4); moderate relief (pain relief about 1/2); significant relief (pain relief about $3 / 4$ ); complete relief (pain disappearance).

Dyspnea: Medical records mentioned in breathing, shortness of breath, gasp, or dyspnea, were equal to dyspnea. Dyspnea relief: 1.Clearly documented alleviation after treatment; 2.If symptoms were not mentioned later, symptoms were deemed to be relieved.

1.2.3 Statistical Analysis: Statistical analyses were performed using SPSS 20.0. Descriptive statistics (e.g. mean, SD, median, interquartile range) was used for analysis, and frequencies were calculated for continuous and categorical data, respectively. For comparison in continuous data/ordinal data and categorical data, we used Wilcoxon rank sum tests and chi-square test. Spearman's rank correlation was used for the correlation test. P-values lower than 0.05 were considered statistically significant.

\subsubsection{Ethics}

The study was approved by the medical ethics committee of West China Fourth Hospital of Sichuan University (No. HXSY-EC-2021027).

\section{Results}

\section{1 demographic characteristics of group $A$ and $B$}

Between January 2012 and November 2019, 80 children were admitted to the Department of Palliative Medicine, West China Fourth Hospital, of whom 41 died during their hospitalisation. There were 24 in the palliative sedation group (Group A) and 17 in the non-palliative sedation group (Group B). The demographic characteristics of the two groups are shown in Table 1. The differences between the two groups were not statistically significant.

Table 1

Demographic characteristics of palliative sedation and non-palliative sedation groups in children

\begin{tabular}{|c|c|c|c|}
\hline Demographic characteristics $(\mathrm{N}=41)$ & $\begin{array}{l}\text { Group A } \\
(n=24)\end{array}$ & $\begin{array}{l}\text { Group B } \\
(n=17)\end{array}$ & $p$ \\
\hline \multicolumn{4}{|l|}{ Age } \\
\hline $0-28$ days & 0 & 3 & 0.228 \\
\hline 29 days -1 year & 3 & 1 & \\
\hline $2-6$ years & 11 & 6 & \\
\hline $7-18$ years & 10 & 7 & \\
\hline \multicolumn{4}{|l|}{ Gender } \\
\hline Male & 15 & 13 & $0.40^{\square}$ \\
\hline Female & 9 & 4 & \\
\hline \multicolumn{4}{|l|}{ Type of disease } \\
\hline Blood tumor & 4 & 3 & 0.564 \\
\hline Solid tumor & 16 & 8 & \\
\hline Congenital disease & 2 & 3 & \\
\hline Diseases of the blood system & 0 & 1 & \\
\hline Severe infection & 2 & 2 & \\
\hline Hydration during hospitalization & 21 & 14 & 0.679 \\
\hline
\end{tabular}


The main symptoms were pain, dyspnea, irritability, fever, coma, vomiting, convulsions (see figure 1). Pain occurring in 28/41(68\%) children was the most common symptom affecting the children's quality of survival at the end of life. Four children in group A got four types of symptoms, ten children got three types, seven children got two types and three children with one symptom. None children got four symptoms in group B, four children got three symptoms, three got two symptoms and ten got one symptom. Distribution of symptoms in two groups see in Table 2. Types of symptoms differed between the two groups, $p=0.013$. The symptoms in group A were more complex than those in group B. But overall symptom relief was higher in A Group which used sedative medication $(p=0.041)$. Five patients in Group B whose symptoms remained unrelieved were fever, abdominal distension, and dyspnea. Three of five were non-tumor. Pain control rate was similarities between the two groups, $95.23 \%$ and $100 \%$ respectively.

Table 2

Types and relief of symptoms in Group A and B

\begin{tabular}{|c|c|c|c|c|c|c|c|c|c|c|c|c|c|c|}
\hline & \multicolumn{6}{|c|}{$\begin{array}{l}\text { Type of symptom } \\
\text { (s) }\end{array}$} & \multicolumn{3}{|c|}{ Symptom control } & \multicolumn{5}{|c|}{ Pain control } \\
\hline & $n$ & 1 & 2 & 3 & 4 & $\mathrm{n}$ & $\begin{array}{l}\text { No } \\
\text { remission }\end{array}$ & remission & $\begin{array}{l}\text { Obvious } \\
\text { remission }\end{array}$ & $\mathrm{n}$ & $\begin{array}{l}\text { No } \\
\text { remission }\end{array}$ & $\begin{array}{l}\text { Mild } \\
\text { remission }\end{array}$ & $\begin{array}{l}\text { Moderate } \\
\text { remissions }\end{array}$ & $\begin{array}{l}\text { Obvious } \\
\text { remissions }\end{array}$ \\
\hline $\begin{array}{l}\text { Group } \\
\text { A }\end{array}$ & 24 & 3 & 7 & 10 & 4 & 24 & 0 & 20 & 4 & $21^{\mathrm{b}}$ & $1^{\mathrm{c}}$ & 2 & 16 & 2 \\
\hline $\begin{array}{l}\text { Group } \\
\text { B }\end{array}$ & 17 & 10 & 3 & 4 & 0 & $15^{\mathrm{a}}$ & 5 & 8 & 2 & $7^{\mathrm{b}}$ & 0 & 2 & 4 & 1 \\
\hline Z & & - & & & & & 2.045 & & & & 0.367 & & & \\
\hline$p$ & 0.01 & & & & & & $0.041^{e}$ & & & & $0.714^{\mathrm{e}}$ & & & \\
\hline \multicolumn{15}{|c|}{ a. 2 cases of coma excluded from 17, were not included in the assessment. } \\
\hline \multicolumn{15}{|c|}{ b. There were no analgesia in 3 cases of Group A and 10 cases of Group B. } \\
\hline \multicolumn{15}{|c|}{ c. too short hospital stay to evaluated. } \\
\hline \multicolumn{15}{|c|}{ d. the exact probability method. } \\
\hline \multicolumn{15}{|c|}{ e. rank sum test. } \\
\hline
\end{tabular}

\subsection{Pain control}

Twenty-one children in Group A used analgesic; besides three patients of Group A were not prescribed for analgesia because the main symptoms were convulsions and moans. In beginning, four children had been prescribed two types of analgesics at the same time, such as hydrocodone sustained-release tablets, acetaminophen and hydrocodone, morphine sulfate solution combined with continuous venous morphine by syringe driver, fentanyl transdermal combined with morphine sulfate solution. The other 16 patients received hydrochloride morphine continuous venous infusion and 1 patient used morphine sulfate oral solution alone. 7 children in group B used analgesic ( $7 / 17$ cases who got fever, coma were not prescribed analgesic, and $3 / 17$ cases who prescribed morphine only beacause of dyspnea were not included in pain assessment). In group $B$ one child used hydrocodone sustained-release tablets, six used morphine continuous venous infusion. Pain scores on admission and after control were higher in group $A$ than in group $B(p=0.014,0.039)$, but there was no significant difference in maximum opioid dosage and pre-death opioid dosage between the two groups. Pain control is shown in Table 3.

Table 3

Pain control in Group A and B

\begin{tabular}{|c|c|c|c|c|c|c|c|c|c|c|}
\hline & \multirow[t]{2}{*}{$\mathbf{N}$} & \multicolumn{3}{|c|}{ Admission } & \multicolumn{3}{|c|}{ After symptom control } & \multirow{2}{*}{$\begin{array}{l}\text { Maximum opioid } \\
\text { dose converted to } \\
\text { oral morphine } \\
\text { dosage/ } 24 \text { hours } \\
\text { (mg) }\end{array}$} & \multirow{2}{*}{$\begin{array}{l}\text { Opioid dose before } \\
\text { death converted to } \\
\text { oral morphine } \\
\text { dosage / } 24 \text { hours } \\
(\mathrm{mg})\end{array}$} & \multirow{2}{*}{$\begin{array}{l}\text { Pain } \\
\text { intensity } \\
\text { difference }\end{array}$} \\
\hline & & $\begin{array}{l}\text { Pain } \\
\text { score }\end{array}$ & $\begin{array}{l}\text { Pain } \\
\text { duration } \\
\text { (hours) }\end{array}$ & $\begin{array}{l}\text { Sleep } \\
\text { (hours) }\end{array}$ & $\begin{array}{l}\text { Pain } \\
\text { score }\end{array}$ & $\begin{array}{l}\text { Pain } \\
\text { duration } \\
\text { (hours) }\end{array}$ & $\begin{array}{l}\text { Sleep } \\
\text { (hours) }\end{array}$ & & & \\
\hline $\begin{array}{l}\text { Group } \\
\text { A }\end{array}$ & 21 & $8(7,10)$ & $24(20,24)$ & $6(4,7)$ & $3(3,4)$ & $4(2.5,7)$ & $8(6,10.5)$ & $30(20,77.5)$ & $30(20,60)$ & $5(4,6.5)$ \\
\hline $\begin{array}{l}\text { Group } \\
\text { B }\end{array}$ & 7 & $7(6,7)$ & $22(18,24)$ & $4(4,5.5)$ & $2(0,3)$ & $4(1.5,13)$ & $9(8,-)$ & $18(9,45)$ & $18(9,45)$ & $4(2,6)$ \\
\hline Z & & -2.501 & -0.095 & -1.481 & -2.068 & -0.065 & 0.615 & -1.358 & -1.278 & -1.004 \\
\hline$p$ & & 0.014 & 0.924 & 0.139 & 0.039 & 0.948 & 0.538 & 0.175 & 0.208 & 0.315 \\
\hline
\end{tabular}


Opioids were the first choice for moderate and severe pain in children at the end of life. In our study, before hospital admission 24 children were treated with morphine sulfate/hydrochloride, 2 with oxycodone hydrochloride, 1 with fentanyl and 1 with acetaminophen and hydrocodone mixture. The forms included sustained-release tablets, oral liquid, injection, and transdermal patches. Two children were treated with two types of opioids (morphine sulfate oral solution + morphine hydrochloride injection, fentanyl transdermal patch + morphine sulfate oral solution). Sixteen cases only used single opioid analgesia, 12 cases used 1-3 adjuvant analgesic drugs, including paracetamol, ketorolac trometamol, scopolamine butyrate, gabapentin capsule, valproate sodium, and ketamine.

\subsection{Dyspnea}

In the study, twelve children had dyspnea, aged 4 days to 14 years. Three patients had dyspnea as single symptom, and other nine combined with pain, irritability, fever, and other symptoms. There were six cases in Group A and six cases in Group B. Both groups had $83 \%$ remission of dyspnea. Both groups used morphine to relieve dyspnea. The survival time and the hospitalization time of the two groups were shown in Table 4(The data are non-normal, expressed in quartile spacing). The sample size of children with dyspnea was too small to analyze.

Table 4

Relief rate and survival time of dyspnea patients in Group A and Group B

\begin{tabular}{|lllll|}
\hline & $\begin{array}{l}\mathbf{n} \\
\text { \%(n) }\end{array}$ & $\begin{array}{l}\text { dyspnea relief rate } \\
\text { (days) }\end{array}$ & $\begin{array}{l}\text { Survival time after diagnosis of disease } \\
\text { a }\end{array}$ & $\begin{array}{l}\text { Hospitalization time }^{\text {a }} \\
\text { (days) }\end{array}$ \\
\hline Group A & 6 & $83 \%(5)$ & $450(253.5,1036.5)$ & $7.5(1,21.5)$ \\
\hline Group B & 6 & $83 \%(5)$ & $63.5(52.5,1855)$ & $12(1.75,51.75)$ \\
\hline a. quartile spacing & & \\
\hline
\end{tabular}

\subsection{Duration of survival and hospitalization time after diagnosis in Group A and Group B.}

The survival time after diagnosis in Group A was 20 days - 2190 days and hospitalization time was 1-85 days. The duration of survival in Group B was 5 days - 5475 days and the length of stay in hospital was 1 - 63 days (see Table 5). Longer survival time after disease diagnosis in group A compared to group $\mathrm{B}(p=0.047)$. However, the hospitalization time before death was similar. Palliative sedation treatment seemed not shorten the hospitalization time of children at the end of life.

Table 5

Survival time after diagnosis and hospitalization time before death in Group A and Group B

\begin{tabular}{|lll|}
\hline & Survival time after diagnosis of disease & Last hospitalization \\
\hline Group A & $365(112.5,730)$ & $9(2.5,22.75)$ \\
\hline Group B & $60(30,795)$ & $3(1,24)$ \\
\hline$Z$ & -1.987 & -0.869 \\
\hline$p$ & 0.047 & 0.385 \\
\hline
\end{tabular}

\subsection{Sedation in Group A}

In electronic records, children(age from 5 months to14 years, 15 males, 4 blood tumors, 16 solid tumors, 2 Congenital diseases, 2 infection, were prescribed sedation drugs. There were one to four main symptoms types (pain, dyspnea, irritability, fever, coma, vomiting, convulsions). Palliative sedation was mainly caused by irritability in 13 cases, convulsion in 5 cases, pain in 7 cases, and dyspnea in 6 cases. Midazolam was used in 17 cases; chlorpromazine was used in 1 case. Six cases used midazolam combined with chlorpromazine. The hospital stays lasted from 1 hour to 85 days, and the use of sedatives lasted from 1 hour to 47 days. The purpose of sedation was to reduce consciousness to control painful symptoms. Before and after sedation, the average Ramsay score was $1(1,1)$ and $2(2,3)$. When death was coming, the deeper sedation score was observed $3(2,4)(p<0.01)$ (see Table 6$)$. Beginning of the sedation, the initial dose of midazolam ranged between $0.5-5 \mathrm{mg} / 24 \mathrm{hours}[\mathrm{mean} 1.5(1$, 2.4) mg/24h]. Maximum dose was 0.5-30 mg/24 hours [mean 3(1,6)mg/24h], and the pre-death dose was $0.5-25 \mathrm{mg} / 24 \mathrm{~h}$ [mean $3(1,5) \mathrm{mg} / 24 \mathrm{~h}$ ]. The maximum dosage of midazolam was similar to that before death $(p=0.066)$. In 4 cases, midazolam was down regulated before death for unknown reasons, but the degree of sedation was not reduced. Midazolam sedation duration did not appear to be associated with maximum dose and pre-death does. 
Table 6

Ramsay scores of sedation group

\begin{tabular}{|ll|}
\hline & Ramsay score ${ }^{\text {a }}$ \\
\hline Pre- sedation score & $1(1,1)$ \\
\hline Sedation score after symptom control & $2(2,3)$ \\
\hline Pre-death sedation score & $3(2,4)$ \\
\hline$X^{2}$ & 34.344 \\
\hline$P^{b}$ & $<0.01$ \\
\hline a. percentile spacing, \\
\hline b. Friedman Inspection \\
\hline
\end{tabular}

\section{Discussion}

There are refractory pain symptoms in children at the end of life. These symptoms seriously affect the quality of life for children and their caregivers' and bring a heavy mental and psychological burden to medical workers $[14,15]$. Palliative sedation consists in consciously reducing the patient's consciousness to alleviate the symptoms. From January 2012 to November 2019, 58.5\% (24/41) of children who died in the palliative care department were treated with palliative sedation, similar to the palliative sedation rate reported in previous studies[25, 30, 31].

End-of-life symptoms of children are complex, and pain is the most common symptom affecting children's quality of life[32, 33], followed by dyspnea, irritability, fever, and other symptoms. Symptom complexity in the palliative sedation group was higher than that in the non-sedation group.

During palliative sedation management, midazolam started from low dosage and was titrated until the refractory symptoms were relieved. Midazolam maximum dosage varies greatly between individuals, and the average Ramsay score after symptom control was 2 (percentile spacing 2-3). Most patients were sedative to 2-3 scores, only two children's Ramsay score was 5 . All sedation were continued to death, sedation duration ranging from 11 hours to 25 days. There was no difference in hospitalization duration between the sedation group and the non-sedation group. Sedation until death should not short the last time of children. During sedation, children were all properly rehydrated and there was no serious damage due to rehydration. Whether is it necessary to change the level of sedation when patients could reach deep sedation? Four children's midazolam dosage were reduced before death, but the level of sedation did not improve.

Opioids were the first choice for moderate and severe pain in children at the end of life[34] (WHO, 2012). In our study, before hospital admission 24 children were treated with morphine sulfate/hydrochloride, 2 with oxycodone hydrochloride, 1 with fentanyl and 1 with acetaminophen and hydrocodone mixture. The forms included sustained-release tablets, oral liquid, injection, and transdermal patches. Two children were treated with two types of opioids (morphine sulfate oral solution + morphine hydrochloride intravenous infusion, fentanyl transdermal patch + morphine sulfate oral solution). Sixteen cases only used single opioid, 12 cases used 1-3 adjuvant analgesic drugs, including paracetamol, ketorolac trometamol, scopolamine butyrate, gabapentin capsule, valproate sodium, and ketamine. Sedation group had higher pain score at admission. Combination of sedative drugs and opioids avoided more opioids doses.

End-of-life dyspnea was treated with pathogenesis treatment, including anti-infection, bronchodilators, glucocorticoids, and other drugs to correct reversible factors. All children with dyspnea used morphine to relieve dyspnea, and six children chose palliative sedation. Both sedation and nonsedation groups achieved a high rate of symptom relief (both $83 \%$ )

This is the first study describing procedures for refractory symptoms for children in end of life. This study found that palliative sedation could relieve refractory symptoms for children in end of life, while could not hasten death. However symptoms of sedation group were more complex than those of non - sedation group, symptom relief rate was higher in sedation group. Titration with a sedative to alleviate suffering was safe management for children in palliative department. Sedation until death should not shorten the last time of children. The presence of multiple symptoms and refractory symptoms makes it easier for doctors and families to make decision to opt for palliative sedation. Midazolam is one of the commonly used drugs for palliative sedation in adults[35]. It is still the first choice for palliative sedation in children in our hospital because of its rapid effect and short duration of action. Severe adverse reactions such as central inhibition and respiratory inhibition were not observed after titration.

It was noted that palliative sedation decision may be associated with symptom complexity, degree of pain, refractory dyspnea, disease course, disease severity and expected survival time, as well as healthcare professionals' perceptions of palliative sedation and parental wishes. All cases were discussed before sedation by a team of palliative medicine experts to determine that the symptoms were refractory, and the disease 
progression was irreversible and children's survival time was limited. Subsequently, a family meeting was organized, and an informed consent form was signed. None of these children attended the communication before sedation because these children were not the legal age to become their agents. All the palliative sedation informed consent forms were signed by their guardian agent.

However, palliative sedation for children seemed effective and safe in this study. Our study was a retrospective study and small sample size. There are fewer children in palliative care than adults or the elderly. Therefore, multi-center clinical studies would be needed for further confirmation.

Palliative sedation was debated by society and medical field. Whether to involve the child in the decision-making discussion about sedation and sedation until death prior to sedation remains an ethical discussion.

\section{Conclusion}

Palliative sedation controls complicated, painful symptoms at the end of life and does not shorten the hospitalization time in children.

\section{Declarations}

\section{Ethics approval and consent to participate}

The study was approved by the medical ethics committee of West China Fourth Hospital of Sichuan University (No. HXSY-EC-2021027).

All methods were carried out in accordance with relevant regulations.And all the palliative sedation informed consent forms were signed by guardian agent of patient.

\section{Consent for publication}

All author agree with submission to BMC Palliative Care.

\section{Availability of data and materials}

The data used and analysed during the current study are available from the corresponding author on reasonable request.

\section{Competing interests}

Not applicable

\section{Funding}

Not applicable

\section{Authors' contributions}

M.D. Yang Chen helped in conceptualization, data collection, data analysis, writing, and editing. Jianjun Jiang and Wei Peng helped in data analysis, writing, and editing. Chuan Zhang helped in conceptualization, data collection, data analysis, and editing.

\section{Acknowledgements}

Authors gratefully acknowledge the patients and participants who involved in this study.

\section{References}

1. Connor S R BMCS: Global atlas of palliative care at the end of life. 2014.

2. Connor SR, Downing J, Marston J: Estimating the Global Need for Palliative Care for Children: A Cross-sectional Analysis. J Pain Symptom Manage 2017, 53(2):171-177.

3. Lu Q, Xiang ST, Lin KY et al: Estimation of Pediatric End-of-Life Palliative Care Needs in China: A Secondary Analysis of Mortality Data From the 2017 National Mortality Surveillance System. J Pain Symptom Manage 2020, 59(6):e5-e8.

4. Wolfe J, Hammel JF, Edwards KE et al: Easing of suffering in children with cancer at the end of life: is care changing? J Clin Oncol2008, 26(10):1717-1723.

5. Schmidt P, Otto M, Hechler T et al: Did increased availability of pediatric palliative care lead to improved palliative care outcomes in children with cancer? J Palliat Med 2013, 16(9):1034-1039. 
6. Groh G, Vyhnalek B, Feddersen B et al: Effectiveness of a specialized outpatient palliative care service as experienced by patients and caregivers. J Palliat Med 2013, 16(8):848-856.

7. Vern-Gross TZ, Lam CG, Graff Z et al: Patterns of End-of-Life Care in Children With Advanced Solid Tumor Malignancies Enrolled on a Palliative Care Service. J Pain Symptom Manage 2015, 50(3):305-312.

8. Ananth P, Melvin P, Berry JG et al: Trends in Hospital Utilization and Costs among Pediatric Palliative Care Recipients. J Palliat Med 2017, 20(9):946-953.

9. Weaver M, Wichman C, Darnall C et al: Proxy-Reported Quality of Life and Family Impact for Children Followed Longitudinally by a Pediatric Palliative Care Team. J Palliat Med 2018, 21(2):241-244.

10. Gans D, Kominski GF, Roby DH et al: Better outcomes, lower costs: palliative care program reduces stress, costs of care for children with lifethreatening conditions. Policy Brief UCLA Cent Health Policy Res 2012(PB2012-3):1-8.

11. Surkan PJ, Kreicbergs $U$, Valdimarsdottir $U$ et al: Perceptions of inadequate health care and feelings of guilt in parents after the death of a child to a malignancy: a population-based long-term follow-up. J Palliat Med 2006, 9(2):317-331.

12. Valdimarsdóttir U, Kreicbergs U, Hauksdóttir A et al: Parents' intellectual and emotional awareness of their child's impending death to cancer: a population-based long-term follow-up study. Lancet Oncol 2007, 8(8):706-714.

13. Snaman JM, Kaye EC, Torres $C$ et al: Helping parents live with the hole in their heart: The role of health care providers and institutions in the bereaved parents' grief journeys. Cancer 2016, 122(17):2757-2765.

14. Olagunju AT, Sarimiye FO, Olagunju TO et al: Child's symptom burden and depressive symptoms among caregivers of children with cancers: an argument for early integration of pediatric palliative care. Ann Palliat Med 2016, 5(3):157-165.

15. Ullrich CK, Rodday AM, Bingen KM et al: Three sides to a story: Child, parent, and nurse perspectives on the child's experience during hematopoietic stem cell transplantation. Cancer 2017, 123(16):3159-3166.

16. Alonso-Babarro A, Varela-Cerdeira M, Torres-Vigil I et al: At-home palliative sedation for end-of-life cancer patients. Palliat Med 2010, 24(5):486-492.

17. Caraceni A, Zecca E, Martini C et al: Palliative sedation at the end of life at a tertiary cancer center. Support Care Cancer 2012, 20(6):12991307.

18. Maeda I, Morita T, Yamaguchi T et al: Effect of continuous deep sedation on survival in patients with advanced cancer (J-Proval): a propensity score-weighted analysis of a prospective cohort study. Lancet Oncol 2016, 17(1):115-122.

19. Diez-Manglano J, Isasi de Isasmendi Perez S, Garcia Fenoll R et al: Palliative Sedation in Patients Hospitalized in Internal Medicine Departments. J Pain Symptom Manage 2020, 59(2):302-309.

20. Twycross R: Reflections on palliative sedation. Palliat Care 2019, 12:1178224218823511.

21. Henderson CM, FitzGerald M, Hoehn KS et al: Pediatrician Ambiguity in Understanding Palliative Sedation at the End of Life. Am J Hosp Palliat Care 2017, 34(1):5-19.

22. Miele E, Angela M, Cefalo MG et al: Propofol-based palliative sedation in terminally ill children with solid tumors: A case series. Medicine (Baltimore) 2019, 98(21):e15615.

23. Pasichow KP, Frizzola M, Miller EG: Palliative Sedation with Oral Medicines in an Infant with Generalized Severe Junctional Epidermolysis Bullosa. J Palliat Med 2018, 21(7):1048-1052.

24. Johnson LM, Frader J, Wolfe J et al: Palliative Sedation With Propofol for an Adolescent With a DNR Order. Pediatrics 2017, 140(2).

25. Korzeniewska-Eksterowicz A, Przyslo L, Fendler W et al: Palliative sedation at home for terminally ill children with cancer. $J$ Pain Symptom Manage 2014, 48(5):968-974.

26. Dworkin RH, Turk DC, Farrar JT et al: Core outcome measures for chronic pain clinical trials: IMMPACT recommendations. Pain 2005, 113(12):9-19.

27. Berde CB, Sethna NF: Analgesics for the treatment of pain in children. N Engl J Med 2002, 347(14):1094-1103.

28. Caraceni A, Hanks G, Kaasa S et al: Use of opioid analgesics in the treatment of cancer pain: evidence-based recommendations from the EAPC. Lancet Oncol 2012, 13(2):e58-68.

29. Wood H, Dickman A, Star A et al: Updates in palliative care - overview and recent advancements in the pharmacological management of cancer pain. Clin Med (Lond) 2018, 18(1):17-22.

30. Maeda S, Kato I, Umeda K et al: Continuous deep sedation at the end of life in children with cancer: experience at a single center in Japan. Pediatr Hematol Oncol 2020, 37(5):365-374.

31. Vallero SG, Lijoi S, Bertin D et al: End-of-life care in pediatric neuro-oncology. Pediatr Blood Cancer 2014, 61(11):2004-2011.

32. Heath JA, Clarke NE, Donath SM et al: Symptoms and suffering at the end of life in children with cancer: an Australian perspective. Med J Aust 2010, 192(2):71-75.

33. Wolfe J, Grier HE, Klar N et al: Symptoms and suffering at the end of life in children with cancer. N Engl J Med 2000, 342(5):326-333. 
34. Organization WH: WHO Guidelines on the Pharmacological Treatment of Persisting Pain in Children with Medical IIInesses. 2012.

35. Lux MR, Protus BM, Kimbrel J et al: A Survey of Hospice and Palliative Care Physicians Regarding Palliative Sedation Practices. Am J Hosp Palliat Care 2017, 34(3):217-222.

\section{Figures}

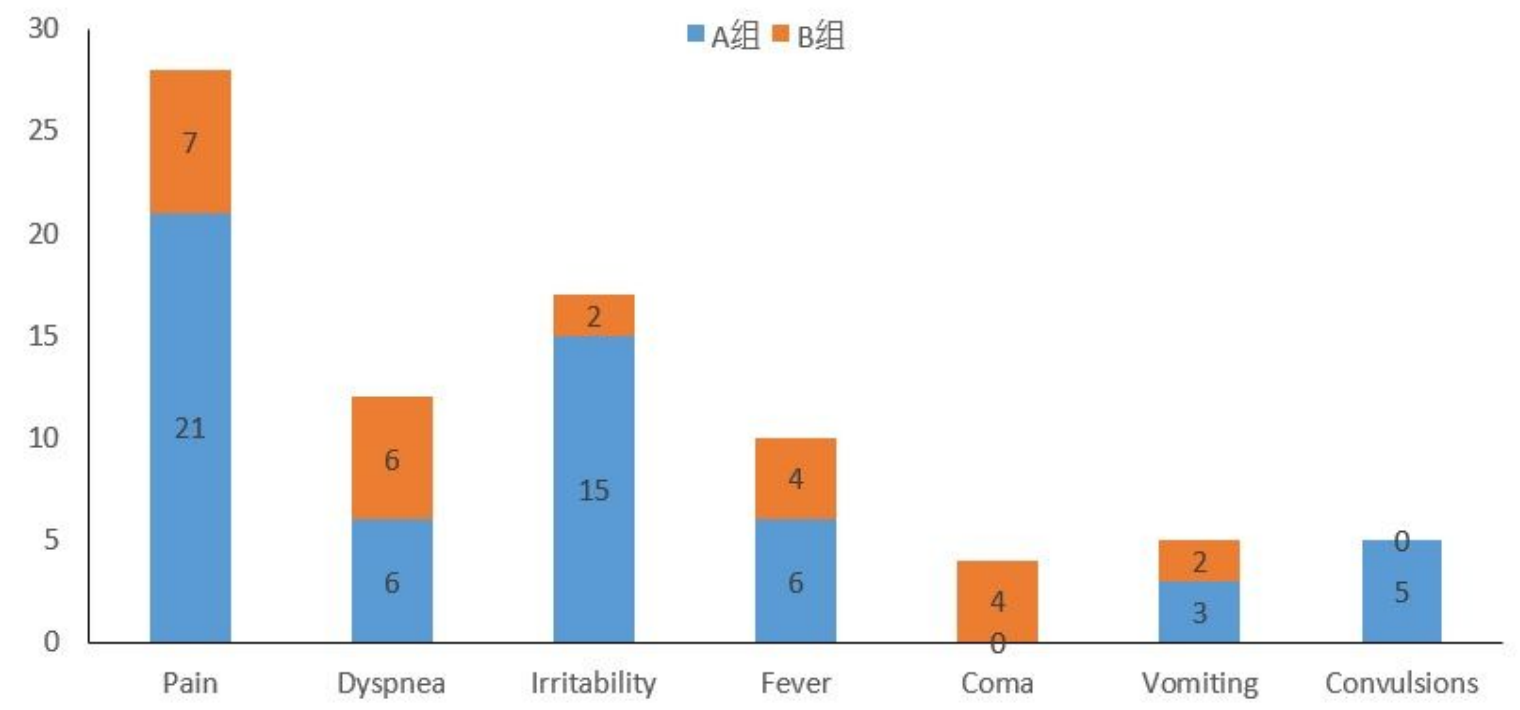

\section{Figure 1}

The distribution of main symptoms in Group A and Group B 